\title{
Incontinence, Bladder Neck Mobility, and Sphincter Ruptures in Primiparous Women
}

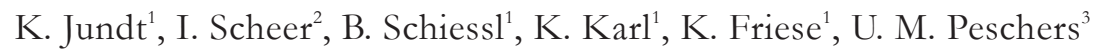 \\ ${ }^{1}$ I. Department of Obstetrics and Gynecology, Beckenbodenzentrum der LMU, Maistrasse, \\ Ludwig-Maximilians-Universitaet, Munich, Germany \\ ${ }^{2}$ Department Gynäkologie, Spitalzentrum Oberwallis, Visp, Swiss, \\ ${ }^{3}$ Beckenboden Zentrum München, Chirurgische Klinik München-Bogenhausen, Munich, Germany
}

\begin{abstract}
Objective: To compare the function of the pelvic floor in primiparae before and during pregnancy with the status post partum concerning symptoms of incontinence, sphincter ruptures, bladder-neck mobility and the influence of the different modes of deliveries.

Methods: Questionnaire evaluating symptoms of urinary and anal incontinence in nulliparous women before and after delivery and correlating these symptoms with functional changes of the pelvic floor based on a careful gynaecologic examination as well as perineal and endoanal ultrasound.

Results: 112 women were included in our study and came for the first visit, 99 women returned for followup 6 months after childbirth. Stress and flatus incontinence significantly increased from before pregnancy $(3$ and $12 \%$ ) to after childbirth (21 and $28 \%$ ) in women with spontaneous delivery or vacuum extraction. No new symptoms occurred after c-section. There was no significant difference between the bladder neck position before and after delivery. The mobility of the bladder neck was significantly higher after vaginal delivery using a vacuum extraction compared to spontaneous delivery or c-section.

The bladder neck in women with post partum urinary stress incontinence was significantly more mobile than in continent controls. The endoanal ultrasound detected seven occult sphincter defects without any correlation to symptoms of anal incontinence.

Conclusion: Several statistically significant changes of the pelvic floor after delivery were demonstrated. Spontaneous vaginal delivery or vacuum extraction increases the risk for stress or anal incontinence, delivery with vacuum extraction leads to higher bladder neck mobility and stress incontinent women have more mobile bladder necks than continent women.
\end{abstract}

Key words: pelvic floor, childbirth, urinary incontinence, anal incontinence, levator ani muscle

\section{INTRODUCTION}

After childbirth about a third of women have urinary incontinence and up to a tenth have some degree of anal incontinence (Hay-Smith et al. 2008).

Whether or not elective cesarean section prevents these symptoms in the long-term is still unclear. After the first delivery, women who had delivered vaginally have two-fold more incontinence than those who had delivered by cesarean section. However, this protective effect of cesarean deliveries on urinary incontinence decreases with age and is not present in older women (Nygaard 2006).

Vaginal delivery (or even the attempt at vaginal delivery) can cause damage to the pudendal nerve, the inferior aspects of the levator ani muscle and fascial pelvic organ supports. Risk factors for such damage have been defined and include, e.g. operative vaginal delivery, a long second stage, or macrosomia. It is much less clear, however, whether such traumata are clinically relevant, and how important they are in the etiology of pelvic floor morbidity later in life (Dietz et al. 2005).

Furthermore vaginal delivery may stretch and/or load the pelvic floor tissue beyond the physiological range and in this way may lead to irreversible changes in tissue properties which play an important role in the urethral support continence mechanism (Wijma et al. 2007).

Hence, myogenic as well as neurogenic damage to the pelvic floor are said to be responsible for the development of incontinence symptoms after delivery.

Perineal ultrasound is a commonly used and easy to handle tool which provides the opportunity to evaluate the bladder neck. Women with bladder neck descent have the risk for developing stress urinary incontinence (Dietz et al. 2005). Whether different modes of delivery (especially spontaneous or operative vaginal delivery) differently influence the bladder neck mobility is not clear.

Endonanal ultrasound shows the morphology of the external and internal anal sphincter. Hereby, defects of both sphincters can be detected, which may not have been detected during childbirth (Andrews et al. 2006). Furthermore, the morphological result of a sphincter repair due to a high degree perineal tear during delivery can be examined and correlated with symptoms of anal incontinence (Vaccaro et al. 2008).

Only few studies compare the pelvic floor before and after delivery, which provides the possibility to differentiate between old and new occurred defects of the pelvic floor due to delivery and to assess the influence of different modes of delivery. An examination 
before pregnancy would be preferable but is seldom possible.

Therefore, the aim of our study was to compare intraindividually the function of the pelvic floor in primiparae before and during pregnancy with the status post partum concerning symptoms of incontinence, sphincter ruptures, bladder neck mobility and the influence of the different modes of deliveries.

\section{Patients and Methods}

The study was undertaken in a Munich University hospital, delivering at this time about 2000 women a year, of which approximately half were nulliparous and eligible for study inclusion. Local Ethics Committee approval was sought and obtained. Women in their first ongoing pregnancy were recruited from the antenatal clinics. Included were those who were more than 32 weeks pregnant, had a singleton pregnancy, were 18 years or older and were able to give informed consent. Exclusion criteria were complicated pregnancies (e.g. multiple pregnancy, macrosomia, fetal growth restriction, fetal malformations, hydramnion, oligohydramnion), women with perineal or vaginal operation in past medical history, preterm rupture of membranes at the time of examination, age less than 18 years, and inability to communicate with care providers because of language difficulties.

Between April 2002 and May 2003112 primiparae with uncomplicated singleton pregnancy and planned vaginal delivery were included in our prospective observational cohort study. All women gave written informed consent and were invited to come to an appointment to the urogynecological department. At the first visit between the $32^{\text {nd }}$ and $37^{\text {th }}$ gestational week and at the second visit 6 months after childbirth, women were asked to fill out a detailed non-validated questionnaire concerning the symptoms of urinary and anal incontinence. This questionnaire assessed the frequency of symptoms (once a month, once a week, several times a week, daily, several times daily) and whether these problems occurred for the first time before or during pregnancy (evaluated at first visit) or after childbirth (evaluated at follow-up visit). To determine the impact on quality of life, a visual analog score was also completed. A pelvic examination was then performed in the lithotomy position. Genital descent was evaluated at rest and straining using the POP-Q grading system proposed by the International Continence Society (Bump et al. 1996). The length of the vaginal introitus and the perineum were measured and women were instructed on the technique of pelvic floor muscle contraction: digital palpation of pelvic muscle strength was graded according to the Oxford scoring system $(0=$ nil, $1=$ flicker, $2=$ weak, $3=$ medium, $4=$ strong, and $5=$ very strong). The test-retest-reproducibility of this score has been established previously (Laycock 1995).

Perineal ultrasound was performed using a 7.5$\mathrm{MHz}$ probe to objectively measure the bladder neck mobility. The bladder neck was visualized in relation to the pubis. An initial scan was performed at rest and at valsalva (excursion). Maximum excursion of the bladder neck during valsalva was encouraged by ask- ing the subjects to bear down while watching their own bladder neck movement on a monitor showing the real-time ultrasound image. A similar method was employed to evaluate maximum bladder neck elevation by imaging the bladder neck while asking the patient to perform a maximum pelvic floor squeeze. Analysis was performed using an $\mathrm{x}-\mathrm{y}$ coordinate system described by Schaer et al. (1995). A reference line was drawn through the axis of the pubic symphysis (x-axis). A second line was then drawn perpendicular to this to intersect at the inferoposterior margin of the symphysis pubis (y-axis). The position of the bladder neck during rest, valsalva, and pelvic floor squeeze could thus be defined by these two coordinates. A negative x coordinate indicated that the bladder neck was positioned to the right of the reference point and a positive value that it was positioned to the left. The bladder neck mobility was measured in centimeters as the length of the vector between the position of the bladder neck at rest and with valsalva (Fig. $1 \mathrm{a}+\mathrm{b})$.

Endoanal ultrasound was performed using a 10 $\mathrm{MHz}$ rotating probe (B\&K Medical, Naerum, Denmark). The technique has been previously described: static images were recorded at four levels (puborectalis, deep, superficial and subcutaneous external sphincter) (Sultan et al. 1994). The ultrasound images were recorded on videotapes. To avoid over-reporting, sphincter defects were considered only if they involved two levels and if both reviewers had identified the defect. Anal sphincter defects were classified into internal, external and combined.

SPSS for Windows Version 15.0 was used for statistical evaluation. $\mathrm{P}<0.05$ was defined as significant. Ttest and $\chi^{2}$-test were used as appropriate.

\section{RESULTS}

112 women were included in our study and came for the first visit, 99 women returned for follow-up 6 months after childbirth. 13 women were lost for follow-up (moved somewhere else and could not be reached by mail or phone). The mean age of these women was 32.7 (SD 4.0) years.

71 of the 112 women $(63.4 \%)$ had a spontaneous vaginal delivery, $20(17.9 \%)$ had a vacuum extraction, one $(0.9 \%)$ a forceps delivery and $20(17.9 \%)$ had a cesarean section. The most frequent indication for cesarean section was failure to progress in the first stage of labor. 69 of the 112 women $(61.6 \%)$ received an epidural analgesia during labor. The average child weight was $3347 \mathrm{~g}(2220-4380 \mathrm{~g}) .11$ women $(9.8 \%)$ had a midline and $19(17.0 \%)$ had a mediolateral episiotomy. Eight times $(7.1 \%)$ a $\mathrm{I}^{\circ}$ perineal tear occurred, 14 times $(12.5 \%)$ a $\mathrm{II}^{\circ}$ and 4 times $(3.6 \%)$ a $\mathrm{III} / \mathrm{IV}^{\circ}$ tear with rupture of the anal sphincter. The results of the questionnaire concerning urinary and anal incontinence are presented in Table 1.

Four of the patients after cesarean section had flatus incontinence before and after childbirth, no new symptoms occurred after this method of delivery. The prevalence of incontinence after different modes of delivery is shown in Table 2. Prolonged second stage of labor ( $>2 \mathrm{hrs})$ in 38 women was clearly correlated 

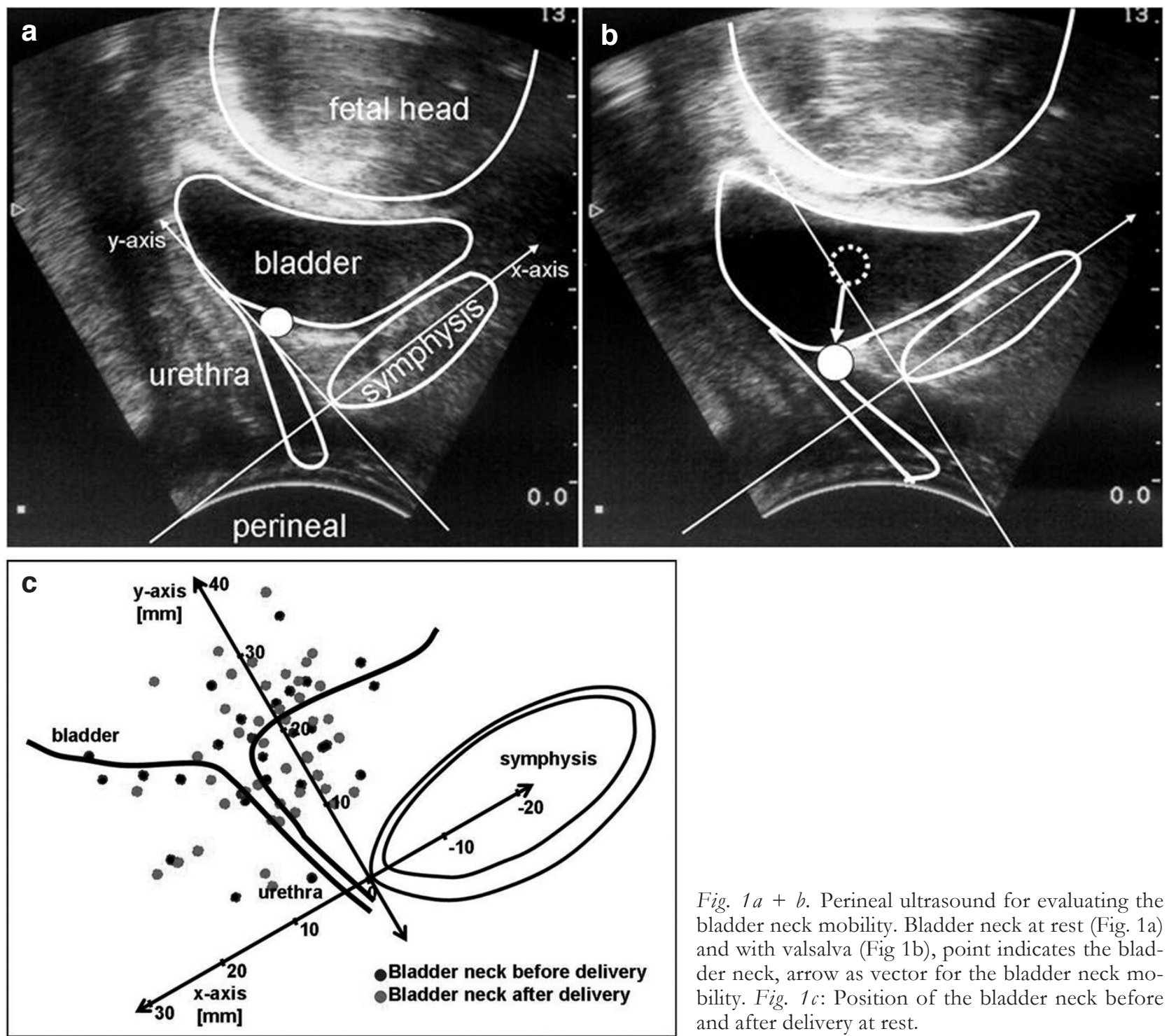

Fig. $1 a+b$. Perineal ultrasound for evaluating the bladder neck mobility. Bladder neck at rest (Fig. 1a) and with valsalva (Fig 1b), point indicates the bladder neck, arrow as vector for the bladder neck mobility. Fig. 1c: Position of the bladder neck before and after delivery at rest.

with the occurrence of anal incontinence (anal incontinence in 19/38 (50.0\%) women with prolonged second stage vs. $11 / 61(18.0 \%)$ without) and ended with a vacuum extraction in 16/38 (42.1\%) women. 6 children had a birth weight of more than 4000g: only three of these women had a vaginal delivery, so no correlation could be established because of the small number of cases.

The differences in pelvic floor function before and after childbirth are presented in Table 3. Two women after spontaneous vaginal delivery developed a vaginal prolapse of more than stage 2 according to the POPQ-system.

Endoanal ultrasound showed no sphincter laceration before childbirth; seven $(7.1 \%)$ occult sphincter defects ( 2 after spontaneous deliveries, 5 after vacuum extractions) in addition to four known sphincter ruptures could be demonstrated post partum. Only two of those eleven women reported flatus incontinence post partum, therefore these sphincter lesions appeared not

Table 1. Urinary and anal incontinence before/during pregnancy and 6 months after childbirth.

\begin{tabular}{lcccl}
\hline$(\mathrm{n}=99)$ & before pregnancy & during pregnancy & 6 months post partum & p-value (before vs. pp) \\
\hline SUI & $\mathbf{3}(\mathbf{3 . 0} \%)$ & $21(21.2 \%)$ & $\mathbf{2 1}(\mathbf{2 1 . 2} \%)$ & $\mathbf{0 . 0 0 1 *}$ \\
OAB & $2(2.0 \%)$ & $4(4.0 \%)$ & $9(9.1 \%)$ & 0.172 \\
Flatus incontinence & $\mathbf{1 2 ( \mathbf { 1 2 . 1 } \% )}$ & $16(16.2 \%)$ & $\mathbf{2 8} \mathbf{( 2 8 . 3 \% )}$ & $\mathbf{0 . 0 2 9 *}$ \\
Fecal urgency & $1(1.0 \%)$ & $0(0.0 \%)$ & $3(3.0 \%)$ & 0.610 \\
Fecal incontinence & $1(1.0 \%)$ & $3(3.0 \%)$ & $3(3.0 \%)$ & 0.610 \\
\hline
\end{tabular}

SUI - Stress Urinary Incontinence, OAB - Overactive Bladder, pp - post partum, ${ }^{*} \chi^{2}$ test significant with $\mathrm{p}<.05$ 
Table 2. Prevalence of incontinence before pregnancy and after different modes of delivery 6 months post partum.

\begin{tabular}{|c|c|c|c|c|c|c|c|}
\hline & \multirow{2}{*}{$\begin{array}{l}\text { Before pregnancy } \\
\qquad(\mathrm{n}=99)\end{array}$} & \multicolumn{2}{|c|}{$\begin{array}{l}\text { Spontaneous delivery } \\
\qquad(\mathrm{n}=61)\end{array}$} & \multicolumn{2}{|c|}{$\begin{array}{l}\text { Vacuum extraction } \\
\qquad(\mathrm{n}=19)\end{array}$} & \multicolumn{2}{|c|}{$\begin{array}{l}\text { Cesarean section } \\
\quad(\mathrm{n}=19)\end{array}$} \\
\hline & & prevalence & p-value* & prevalence & p-value* & prevalence & p-value* \\
\hline SUI & $3(3.0 \%)$ & $14(23.0 \%)$ & 0.002 & $7(36.8 \%)$ & 0.001 & $0(0 \%)$ & 1.00 \\
\hline $\mathrm{OAB}$ & $2(2.0 \%)$ & $7(11.5 \%)$ & 0.30 & $1(5.2 \%)$ & 1.00 & $1(5.2 \%)$ & 1.00 \\
\hline Anal inc. & $13(13.1 \%)$ & $22(36.1 \%)$ & 0.0016 & $8(42.1 \%)$ & 0.007 & $4(21.1 \%)$ & 0.58 \\
\hline
\end{tabular}

SUI - Stress Urinary Incontinence, OAB - Overactive Bladder, $* \chi^{2}$ test, comparison against prevalence before pregnancy; bold numbers: significant difference with $\mathrm{p}<.05$

Table 3. Quantitative parameters assessed during pregnancy and after childbirth.

\begin{tabular}{|c|c|c|c|c|c|c|c|}
\hline & \multirow{2}{*}{$\begin{array}{l}\text { During pregnancy } \\
\qquad(\mathrm{n}=99)\end{array}$} & \multicolumn{2}{|c|}{$\begin{array}{l}\text { Spontaneous delivery } \\
\qquad(\mathrm{n}=61)\end{array}$} & \multicolumn{2}{|c|}{$\begin{array}{l}\text { Vacuum extraction } \\
\qquad(\mathrm{n}=19)\end{array}$} & \multicolumn{2}{|c|}{$\begin{array}{c}\text { Cesarean section } \\
(\mathrm{n}=19)\end{array}$} \\
\hline & & $\begin{array}{l}\text { Mean value } \\
\text { (s.d.) }\end{array}$ & p-value* & $\begin{array}{l}\text { Mean value } \\
\text { (s.d.) }\end{array}$ & p-value* & $\begin{array}{l}\text { Mean value } \\
\text { (s.d.) }\end{array}$ & p-value* \\
\hline $\begin{array}{l}\text { LAM contraction } \\
\text { (Oxford score } 0-5)\end{array}$ & $2.96(1.05)$ & $2.75(1.20)$ & 0.45 & $2.82(1.19)$ & 0.60 & $2.97(1.09)$ & 0.96 \\
\hline $\begin{array}{l}\text { Length of introitus } \\
(\mathrm{cm})\end{array}$ & $2.85(0.58)$ & $2.93(0.61)$ & 0.407 & $2.88(0.69)$ & 0.83 & $2.75(0.77)$ & 0.10 \\
\hline $\begin{array}{l}\text { Length of perineum } \\
(\mathrm{cm})\end{array}$ & $3.77(0.80)$ & $2.96(0.59)$ & 0.0018 & $2.78(0.53)$ & 0.001 & $3.06(0.47)$ & 0.0029 \\
\hline $\begin{array}{l}\text { Thickness of M. } \\
\text { *sphincter ani ext. } \\
(\mathrm{cm})\end{array}$ & $0.83(0.17)$ & $0.79(0.15)$ & 0.248 & $0.78(0.16)$ & 0.23 & $0.83(0.19)$ & 1.00 \\
\hline $\begin{array}{l}\text { Thickness of M. } \\
\text { sphincter ani int. } \\
(\mathrm{cm})\end{array}$ & $0.20(0.06)$ & $0.21(0.08)$ & 0.611 & $0.21(0.07)$ & 0.51 & $0.19(0.06)$ & 0.50 \\
\hline
\end{tabular}

LAM - Levator ani muscle, ${ }^{*}$ t-test comparison against values during pregnancy; bold numbers: significant difference with $\mathrm{p}<.05$

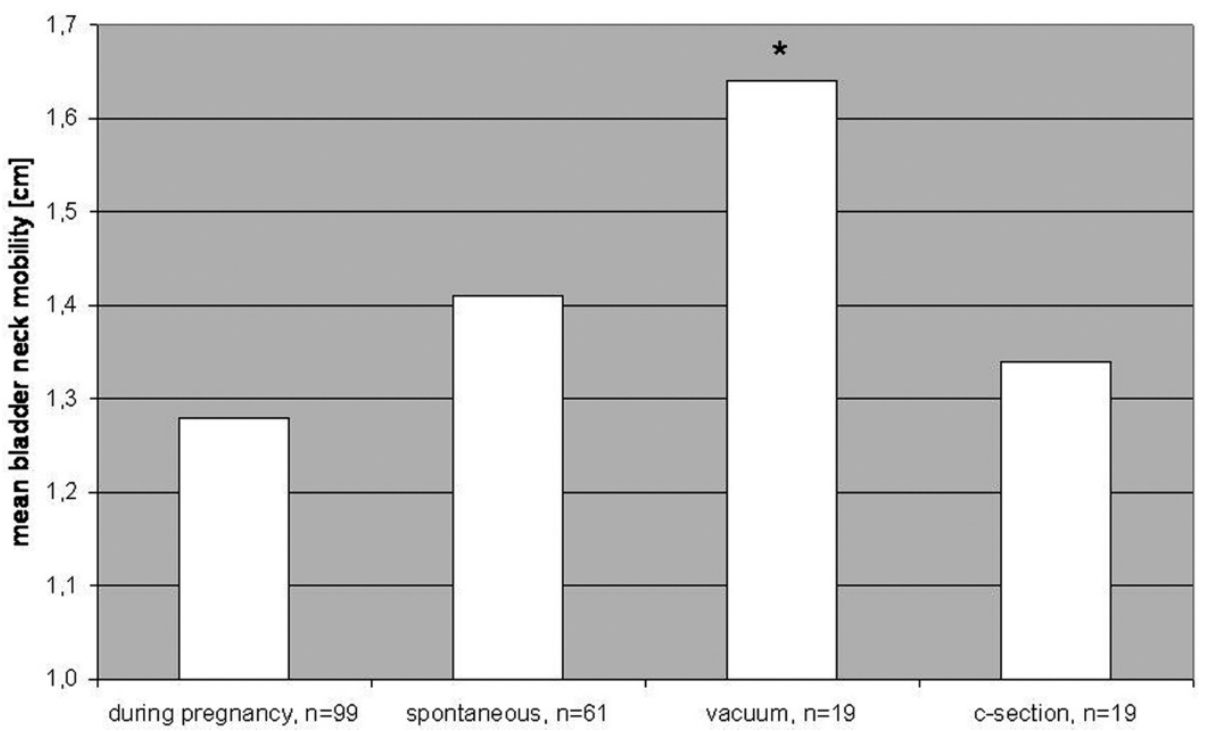

Fig. 2. Mean of bladder neck mobility during pregnancy and after different modes of delivery, * t-test significant with $\mathrm{p}<.05$, during pregnancy vs. vacuum delivery. correlated to the presence of symptoms of anal incontinence after childbirth.

Perineal ultrasound showed no significant difference between the position of the bladder neck at rest before and after delivery. (Fig.1c) The mobility of the bladder neck was significantly higher after vaginal delivery using a vacuum extraction compared to spontaneous delivery or cesarean section. (Fig. 2) Women 


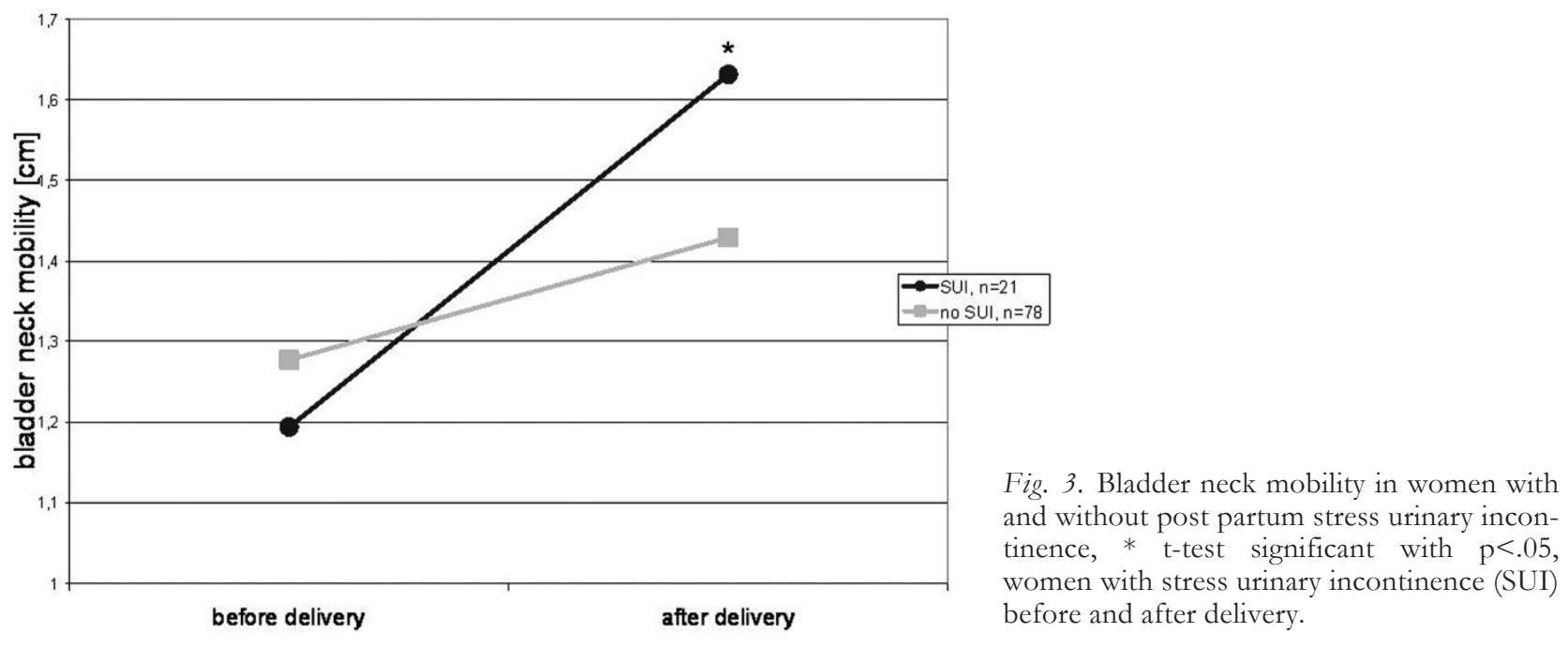

with stress urinary incontinence (SUI) after delivery had significantly more mobile bladder necks during valsalva maneuver. (Fig. 3)

\section{Discussion}

To our knowledge, this is the first study not only evaluating symptoms of urinary and anal incontinence in nulliparous women before and after delivery but also correlating these symptoms with functional changes of the pelvic floor using a careful gynaecologic examination as well as perineal and endoanal ultrasound. Thereby, our study could demonstrate several statistically significant changes of the pelvic floor after delivery. In contrast to most other studies, we included women during pregnancy for pelvic floor examination. This has the obvious advantage of avoiding a bias caused by the fact that only (or predominantly) women with complaints after childbirth show up.

Our return rate of $88.4 \%$ was good and resulted in a sufficient number of women to draw statistically valid conclusions.

The mean age of the included primiparous women was relatively high with 32.7 years reflecting the development in our society that the age among academic primiparous women (the majority of the included women had college degrees) increases. The mode of delivery among our patients shows about 60\% spontaneous deliveries, 20\% instrumental deliveries and 20\% cesarean sections which is quite representative for women at term in our university hospital. The mode of instrumental delivery depends largely on the consultant on call. The majority prefers to use vacuum extraction in this situation.

The occurrence of urinary and fecal incontinence during pregnancy and 6 months after delivery was evaluated using a none-validated questionnaire since, at this time, no validated questionnaire on urinary and fecal incontinence was available in German language.

Urinary stress and flatus incontinence significantly increased from before pregnancy ( 3 and $12 \%$ ) to after childbirth (21 and 28\%) in women with spontaneous delivery or vacuum extraction. This is in agreement with the Norwegian Epincont-Study (Rortveit et al.
2003), where an increased risk of urinary incontinence after vaginal delivery and even after c-section compared to nulliparous women was shown. In our study, no new symptoms occurred after cesarean section. Failure to progress in the first stage of labor was the reason for the c-section in 13 of 20 women.

The discussion about the possible protective effect of an elective c-section on the pelvic floor is still in progress: Altmann and colleagues describe that incontinence symptoms are more common following spontaneous vaginal delivery when compared with cesarean section 10 years after first delivery. However, cesarean section is not associated with a major reduction of anal and urinary incontinence (Altmann et al. 2007). On the other hand, Boyles et al. found in a study in 5599 primiparous women that indeed vaginal delivery increases the risk of urinary incontinence, but they could not show a statistical difference in the incidence of urinary incontinence among those women who had elective cesarean deliveries $(6.1 \%)$, women who had cesarean deliveries after laboring (5.7\%), and women who had cesarean deliveries after laboring and pushing (6.4\%) (Boyles et al. 2009). On the contrary Herrmann et al. could only show a significant correlation between parity and SUI. Pregnancy possibly predisposes to SUI 3 years after delivery as well as parity, but a significant correlation between the mode of delivery and SUI was not found (Herrmann et al. 2008). Our results suggest that caesarean section has a protective effect on symptoms of urinary and anal incontinence, at least 6 months after delivery.

Apart from the perineal length our study showed no significant changes of the quantitative parameters of the pelvic floor after childbirth. This is in accordance with Peschers et al. who could demonstrate an impairment of pelvic floor muscle strength immediately after vaginal birth, whereas two months after delivery no significant differences to the antepartum values could be measured (Peschers et al. 1997). With respect to the observed significant decrease of perineal length we could not find any other published data comparing the perineal length before and after childbirth. Existing studies focused on the correlation between perineal length and the extent of perineal laceration (Kalis et al. 2005). 
There was no significant difference between the bladder neck position before and after delivery. This is in contrary to Peschers et al. who described a shift of the bladder neck position dorsocaudally after delivery compared to antenatal (Peschers et al. 1996). However, the time of our first examination in the third trimenon was relatively late during pregnancy. Therefore the pressure of the fetal cephalic/gravid uterus and the hormonal loosening of the pelvic floor tissue might already lead to a lowering of the bladder neck position which was about the same 6 months post partum.

The mobility of the bladder neck was significantly higher after vaginal delivery using a vacuum extraction compared to spontaneous delivery or c-section. This is in accordance to Toozs-Hobson and coworkers who stated that postpartum bladder neck mobility was also significantly greater in women who delivered vaginally compared to women with c-section. They did, however, not differentiate between women after spontaneous or operative vaginal delivery (Toozs-Hobsonet al. 2008). A positive correlation between the increase of bladder neck mobility and the post partum appearance of stress urinary incontinence was also significant in our study.

The endoanal ultrasound showed no sphincter laceration before childbirth; after delivery eleven (occult) sphincter defects could be demonstrated after vaginal delivery. Only two of these eleven women reported symptoms of anal incontinence.

Injury to the anal sphincter may occur during a vaginal or cesarean delivery from direct injury to the muscles or neurological damage (Yilmaz et al. 2008, Sultan et al. 1993, Snooks et al. 1984, Deen et al. 1993, Allen et al. 1990). Direct injury to the muscles is usually a complication of a woman's first delivery (Sultan et al. 1993) and damage to the nerves is usually a complication of subsequent deliveries (Snooks et al 1990). The pressure applied by the enlarged uterus and fetus can damage the nerves in the pubococcygeus muscle and external anal sphincter and cause fecal incontinence. This condition is aggravated in women with prolonged labor and/or who gave birth to a child weighing more than $4000 \mathrm{~g}$. Vaginal delivery may add perineal lacerations to the injury (Snooks et al. 1986), and anal sphincter function can be also disturbed when cesarean delivery is performed after active labor has started (Fynes et al. 1998). The rates of anal sphincter damage vary widely among studies because many affected women are not symptomatic. Sultan et al. found $20.4 \%$ of patients and Abramowitz et al. $23.1 \%$ of patients to be symptomatic, whereas Fynes et al. found $68 \%$ of patients to be symptomatic (Sultan et al. 1993, Abramowitz et al. 2000, Fynes et al. 1998).

A certain limitation of our study is the relatively late inclusion of the women between the $32^{\text {nd }}$ and $37^{\text {th }}$ week of gestation. In Germany, women with inconspicuous pregnancy usually have their controls at their outpatient specialist. They only once present in the hospital they want to deliver at during the third trimester, therefore women in earlier stages of pregnancy were rarely reachable for us. Furthermore, the time period of observation with 6 months after delivery was relatively short. Some problems concerning urinary or fecal incontinence might occur later or during menopause when hormonal support of the pelvic floor tissue diminishes. Therefore we plan to further follow-up those women over a longer period of time.

In conclusion, our study showed that there are multiple significant changes of the pelvic floor after childbirth. We could demonstrate a significant increase of urinary and flatus incontinence after vaginal delivery, while no women with cesarean section had new occurring symptoms of incontinence after delivery. Women with stress urinary incontinence six months post partum showed a significant increase in bladder neck mobility. Apart from a decrease in perineal length after delivery, the quantitative parameters of the pelvic floor showed no difference before and after childbirth. The number of occult sphincter defects with 7 in 99 women was very high in our collective, but did not correlate with symptoms of anal incontinence. Further investigation is undoubtedly needed into the complex relationship that different modes of delivery may have on the pelvic floor and its consequent function. Randomized interventional trials in this area are difficult because of ethical constraints, but are needed to draw any conclusion about the mode of delivery and the subsequent development of urogynecological problems.

\section{REFERENCES}

1. Abramowitz L, Sobhani I, Ganansia R, et al. Are sphincter defects the cause of anal incontinence after vaginal delivery? Results of a prospective study. Dis Colon Rectum 2000;43(5):590-6.

2. Allen RE, Hosker GL, Smith ARB, Warren DW. Pelvic floor damage and childbirth: a neurophysiological study. Br J Obstet Gynaecol 1990;97(9):770-9.

3. Altman D, Ekström A, Forsgren C, Nordenstam J, Zetterström J. Symptoms of anal and urinary incontinence following cesarean section or spontaneous vaginal delivery. Am J Obstet Gynecol. 2007 Nov;197(5):512.e17.

4. Andrews V, Sultan AH, Thakar R, Jones PW. Occult anal sphincter injuries - myth or reality? BJOG. 2006 Feb; 113(2):195-200.

5. Boyles SH, Li H, Mori T, Osterweil P, Guise JM. Effect of Mode of Delivery on the Incidence of Urinary Incontinence in Primiparous Women. Obstet Gynecol. 2009 Jan;113(1):134-141.

6. Bump RC, Mattiasson A, Bø K, et al. The standardization of terminology of female pelvic organ prolapse and pelvic floor dysfunction. Am J Obstet Gynecol. 1996 Jul;175(1): 10-7.

7. Deen KI, Kumar D, Williams JG, Olliff J, Keighley MR. The prevalence of anal sphincter defects in faecal incontinence: a prospective endosonic study. Gut 1993;34(5): 685-8.

8. Dietz HP, Clarke B, Herbison P. Bladder neck mobility and urethral closure pressure as predictors of genuine stress incontinence. Int Urogynecol J Pelvic Floor Dysfunct. 2002;13(5):289-93.

9. Dietz HP, Wilson PD. Childbirth and pelvic floor trauma. Best Pract Res Clin Obstet Gynaecol. 2005 Dec;19(6): 913-24. Epub 2005 Sep 22.

10. Fynes M, Donnely VS, O'Connell PR, O'Herlihy C. Cesarean delivery and anal sphincter injury. Obstet Gynecol 1998;92(4 pt 1): 496-500.

11. Hay-Smith J, Mørkved S, Fairbrother KA, Herbison GP. Pelvic floor muscle training for prevention and treatment 
of urinary and faecal incontinence in antenatal and postnatal women. Cochrane Database Syst Rev. 2008 Oct 8;(4):CD007471

12. Herrmann V, Scarpa K, Palma PC, Riccetto CZ. Stress urinary incontinence 3 years after pregnancy: correlation to mode of delivery and parity. Int Urogynecol J Pelvic Floor Dysfunct. 2008 Nov 20.

13. Kalis V, Chaloupka P, Turek J, Rokyta Z. [The perineal body length and injury at delivery] Ceska Gynekol. 2005 Sep;70(5):355-61.

14. Laycock J. Pelvic Floor Dysfunction, Ph.D. Thesis. Bradford University; 1995.

15. Nygaard I. Urinary incontinence: is cesarean delivery protective? Semin Perinatol. 2006 Oct;30(5):267-71.

16. Peschers U, Schaer G, Anthuber C, Delancey JO, Schuessler B. Changes in vesical neck mobility following vaginal delivery. Obstet Gynecol. 1996 Dec;88(6):1001-6

17. Peschers U, Schaer GN, DeLancey JO, Schussler B (1997). Levator ani function before and after childbirth. Br J Obstet Gynaecol 104:1004-1008.

18. Rortveit G, Daltveit AK, Hannestad YS, Hunskaar S; Norwegian EPINCONT Study. N Engl J Med. 2003 Mar 6;348(10):900-7

19. Schaer GN, Koechli OR, Schuessler B, Haller U. Perineal ultrasound for evaluating the bladder neck in urinary stress incontinence. Obstet Gynecol 1995; 85(220):224.

20. Snooks SJ, Swash M, Henry MM, Setchell M. Risk factors in childbirth causing damage to the pelvic nerve innervation. Int J Colorectal Dis 1986;1(1):20-4.

21. Snooks SJ, Swash M, Mathers SE, Henry MM. Effect of vaginal delivery on the pelvic floor: a 5-year follow-up. $\mathrm{Br}$ J Surg 1990;77(12):1358-60.

22. Snooks SJ, Swash M, Setchell M, Henry MM. Injury to innervation of pelvic floor sphincter musculature in childbirth. Lancet 1984;2(8402):546-50.

23. Sultan AH, Kamm MA, Hudson CN, Bartram C. Analsphincter disruption during vaginal delivery. $\mathrm{N}$ Engl J Med 1993;329(26): 1905-11.
24. Sultan AH, Kamm MA, Hudson CN, Nicholls JR, Bartram CI. Endosonography of the anal sphincters: normal anatomy and comparison with manometry. Clin Radiol 1994:49:368-74.

25. Toozs-Hobson P, Balmforth J, Cardozo L, Khullar V, Athanasiou S. The effect of mode of delivery on pelvic floor functional anatomy. Int Urogynecol J Pelvic Floor Dysfunct. 2008 Mar;19(3):407-16. Epub 2007 Sep 26.

26. Vaccaro C, Clemons JL. Anal sphincter defects and anal incontinence symptoms after repair of obstetric anal sphincter lacerations in primiparous women. Int Urogynecol J Pelvic Floor Dysfunct. 2008 Nov;19(11):1503-8. Epub 2008 Jun 12.

27. Wijma J, Weis Potters AE, van der Mark TW, Tinga DJ, Aarnoudse JG. Displacement and recovery of the vesical neck position during pregnancy and after childbirth. Neurourol Urodyn. 2007;26(3):372-6.

28. Yilmaz E, Nas T, Korucuoglu U, Guler I. Manometric evaluation of anal sphincter function after vaginal and cesarean delivery. Int J Gynaecol Obstet. 2008 Nov;103(2): 162-5. Epub 2008 Aug 21.

Received: October 15, 2009 / Accepted: February 10, 2010

Address for correspondence:

Katharina Jundt, M.D.

Department for Gynecology and Obstetrics

Ludwig-Maximilians-Universität

Maistr. 11

80337 München

Germany

Phone: +49-89-5160-4111

Fax: +49-89-5160-4166

E-mail: katharina.jundt@med.uni-muenchen.de 